\title{
Follicular thyroid carcinoma metastatic to skin: a small papule and a big diagnostic change*
}

\author{
Marcia Lanzoni Alvarenga Lira ${ }^{1}$, Mariana Abdo de Almeida ${ }^{2}$, Michele Maria Reis-Feroldi ${ }^{3}$, \\ Jeanine Alvarenga Rocha ${ }^{4}$
}

DOI: http:/ / dx.doi.org/10.1590/abd1806-4841.20198299

\begin{abstract}
Cutaneous metastases are uncommon in daily practice, although very important, since they may be the first manifestation of an undiscovered primary neoplasm or the first indication of recurrence. Cutaneous metastases from the breast are the most frequent in women and cutaneous metastases from the lung are the most frequent in men. Thyroid carcinoma, despite representing the most frequent endocrine neoplasm, is considered a rare neoplasm, corresponding to $1 \%$ of malignant neoplasms diagnosed. Cutaneous metastases from follicular carcinoma are rare and occur mainly in the head and neck area. We report a case of cutaneous metastasis in a patient with follicular thyroid carcinoma and breast carcinoma. Because of the association of these two neoplasms, the possibility of Cowden Syndrome - multiple hamartoma syndrome - was raised, but was excluded by genetic analysis of PTEN gene.
\end{abstract}

Keywords: Neoplasm metastasis; Hamartoma syndrome, multiple; PTEN Phosphohydrolase; Thyroid neoplasms

\section{CASE REPORT}

A 55-year-old female presented an erythematous, asymptomatic papule of $0.5 \mathrm{~cm}$ in diameter on her left anterior neck, just above a midline transverse scar caused by a thyroidectomy. (figure1) Excisional biopsy was performed. The histopathological examination showed a well-demarcated lesion of cells in trabecular and glandular arrangement (Figure 2). The cells displayed enlarged and hyperchromatic nuclei and frequent mitotic figures, including atypical ones (Figure 3). Occasionally, there was eosinophilic secretion in the lumen (Figure 4). The cells did not show nuclear grooves or pseudoinclusions. The main differential diagnoses considered were a primary adnexal carcinoma and metastatic thyroid carcinoma. The tissue was submitted to immunohistochemical analysis which was positive for anti-cytokeratin and anti-thyroglobulin - cytokeratin markers of 40, 48, 50 and 50.6 kDa and AE1/ AE3 clones - confirming the diagnosis of a primary thyroid tumor (Figure 5).

The patient had a previous history of thyroid nodule in the left lobe, six years before, diagnosed as follicular adenoma after subtotal thyroidectomy, invasive ductal carcinoma in the left breast diagnosed four years ago and lung hamartoma in the lower left lobe. She also had a maternal family history of ovarian cancer.

\footnotetext{
Received 15 March 2018

Accepted 22 May 2018

* Work conducted at the Laboratório do Vale, Taubaté (SP), Brazil.

Financial support: None.

Conflict of interest: None.

Department of Pathology, Laboratório do Vale, Taubaté (SP), Brazil

Medical student, Universidade de Taubaté, Taubaté (SP), Brazil.

Private practice, Campos do Jordão (SP), Brazil.

Department of Pathology, Laboratório Bacchi, Botucatu (SP), Brazil.
}

\section{MaILING AdDRESS:}

Mariana Abdo de Almeida

E-mail: abdomed@bol.com.br 


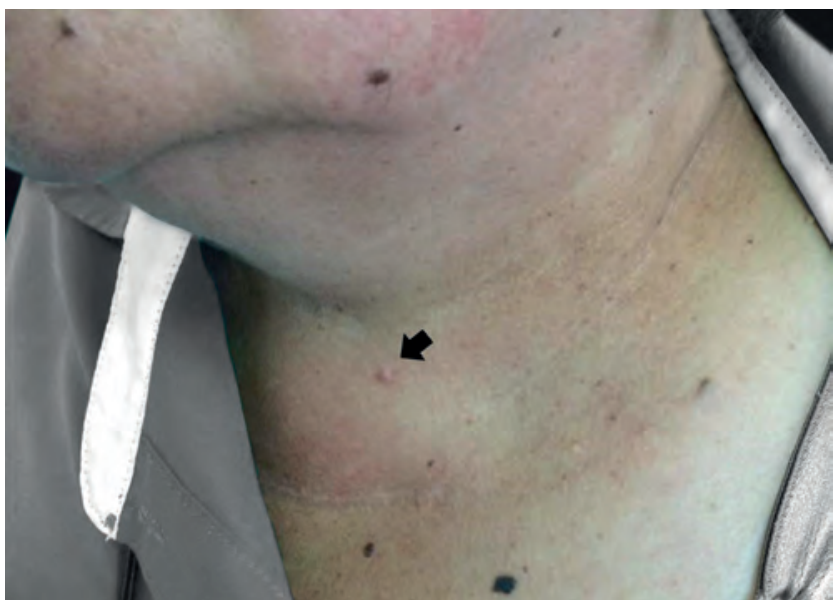

FiguRE 1: A $0.5 \mathrm{~cm}$ papule on the left anterior neck, above a crosssectional thyroidectomy scar.
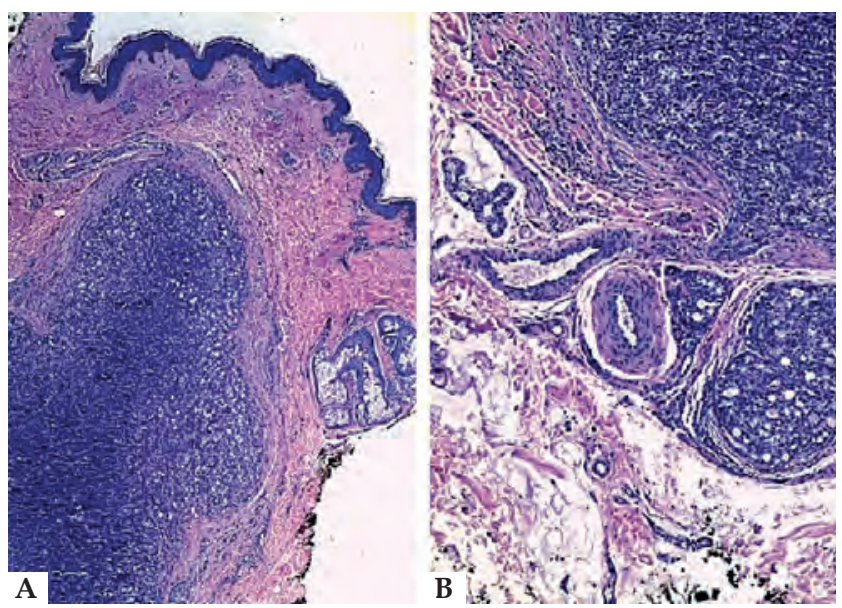

Figure 2: Well demarcated lesion with a trabecular and glandular arrangement. Hematoxylin and eosin A - superficial portion, x40. B - deep portion, $x 100$

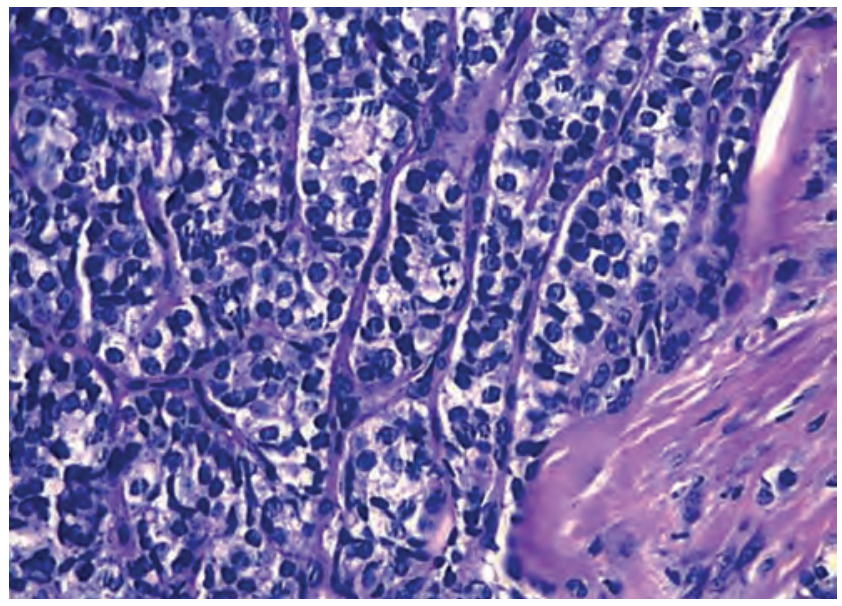

FIGURE 3: The cells showed enlarged, hyperchromatic nuclei and frequent mitotic figures, some of them atypical. Hematoxylin and eosin, $x 400$

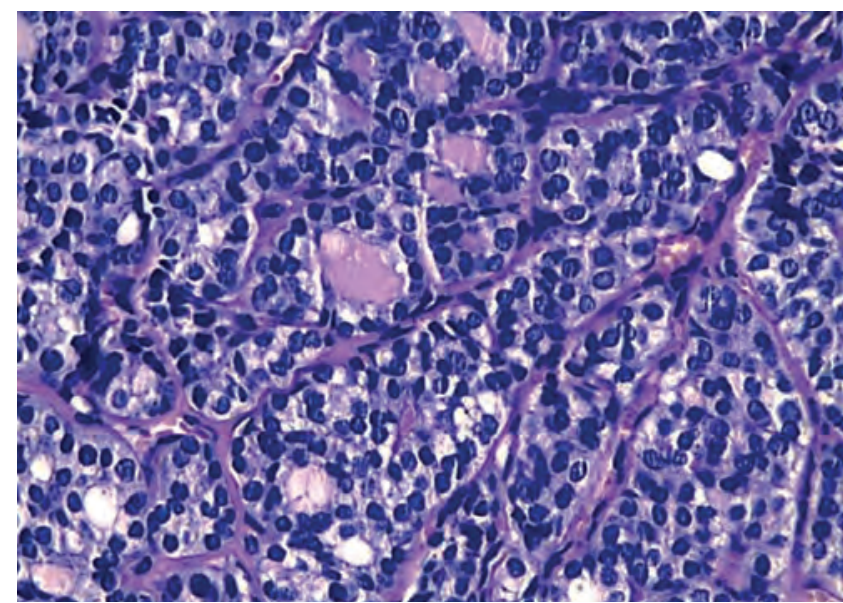

Figure 4: Occasionally, there was eosinophilic secretion in the lumen. Hematoxylin and eosin, $x 400$

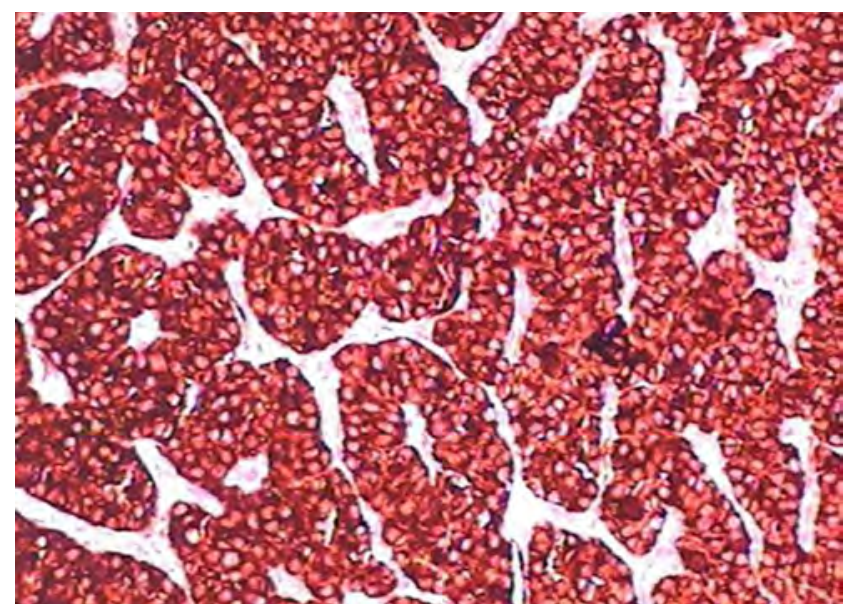

Figure 5: Positive immunohistochemistry panel for antithyroglobulin. Immunoperoxidase, x100. Marker: thyroglobulin; clone: polyclonal

The association of breast cancer and follicular thyroid carcinoma fulfilled criteria for an operational diagnosis of Cowden syndrome (CS) according to National Comprehensive Cancer Network (NCCN) 2015. ${ }^{1}$ Therefore, she was referred to the genetic service for testing of PTEN mutation, which result was negative for allelic variants, deletion or duplication of exons.

\section{DISCUSSION}

In this case, the diagnosis of cutaneous metastasis from thyroid follicular carcinoma was essential once her previous follicular thyroid lesion was reclassified (it was a carcinoma, not an adenoma). There is a similar case reported where a 53-year-old woman underwent subtotal thyroidectomy because of the clinical suspicion of malignancy, but the histological examination of the resected tissue did not confirm it. Eight years later, she developed cutaneous metastasis next to the operation site on the neck. ${ }^{2}$ These cases highlight the difficulty in differentiating follicular carcinoma from adenoma. 
Cutaneous metastases (CM) are infrequent in dermatology. ${ }^{3,4}$ They may be the first manifestation of a primary tumor or may indicate a recurrence. ${ }^{5} \mathrm{CM}$ from thyroid carcinoma are rare, and those from follicular carcinoma can exhibit a wide of histologic variety. $2,6,7$

Thyroid carcinoma survivors are prone to developing breast carcinoma more often than the general population. In these cases, it occurs at younger age, has more estrogen/progesterone receptor positivity, has higher incidence of mixed invasive cancer and appears, on average, five years after diagnosis of the thyroid tumor. ${ }^{8}$

The association between thyroid and breast lesions raised the suspicion of CS. Despite the absence of pathognomonic lesions (trichilemmomas, acral keratoses and oral papillomatous lesions), she fulfilled criteria for operational diagnosis - the presence of follicular thyroid carcinoma and breast carcinoma, constituting two major criteria. Recently, a mutation risk calculator, the Cleveland Clinic score, has been developed to estimate the risk of having a PTEN mutation based on the medical history. ${ }^{9}$ Based on current answers, her score was 6 , corresponding to a mutation probability of less than $1 \% .{ }^{10}$

It was extremely important to exclude CS, since this disease can present with malignant disorders in internal organs, mainly in thyroid, breast and gastrointestinal tract. Also, this diagnosis has implications for her future generations - it is a disease of autosomal dominant inheritance.

In summary, the finding of a small papule on the patient's neck and its proper diagnosis led to a substantial shift in the previous diagnosis of her thyroid lesion, from benign to malignant, with metastasis. Together with the knowledge of her previous history, a genetic syndrome was suspected and excluded by molecular tests. This case highlights the role of clinical-pathological correlation in achieving the correct diagnosis and the importance of the dermatologist in suspecting malignant diseases from the finding of specific lesions. $\square$

\section{REFERENCES}

1. Ncbi.nIm.nih.gov [Internet]. Eng C. PTEN Hamartoma Tumor Syndrome. In: Adam MP, Ardinger HH, Pagon RA, Wallace SE, editors. GeneReviews ${ }^{\circledR}$. Seattle (WA): University of Washington, Seattle; 1993-2018 [updated 2016 Jun 2; cited 2017 Nov 23]. Available from: https://www.ncbi.nlm.nih.gov/books/NBK1488/.

2. Tronnier M, Winzer M, Wolff HH. Cutaneous metástases from follicular thyroid carcinoma: histology, immunehistology, and electron microscopy. A report of two cases. Dermatologica. 1991;183:286-9.

3. McWhorter JE, Cloud AW. Malignant tumors and their metastases: a summary of the necropsies on eight hundred sixty-five cases performed at the Bellevue Hospital of New York. Ann Surg. 1930;92:434-43.

4. Krathen RA, Orengo IF, Rosen T. Cutaneous metastasis: a meta-analysis of data. South Med J. 2003;96:164-7.

5. Weimann ET, Botero EB, Mendes C, Santos MA, Stelini RF, Zelenika CR. Cutaneous metastasis as the first manifestation of occult malignant breast neoplasia. An Bras Dermatol. 2016;91(Suppl 1):S105-7.
6. Schlumberger MJ. Papillary and follicular thyroid carcinoma. N Engl J Med. 1998;338:297-306.

7. Quinn TR, Duncan LM, Zembowicz A, Faquin WC. Cutaneous metastases of follicular thyroid carcinoma: a report of four cases and a review of the literature. Am J Dermatopathol. 2005;27:306-12.

8. Kuo JH, Chabot JA, Lee JA. Breast cancer in thyroid cancer survivors: Ananalysis of the Surveillance, Epidemiology, and End Results-9 data base. Surgery. 2016;159:23-9.

9. Tan MH, Mester J, Peterson C, Yang Y, Chen JL, Rybicki LA, et al. A clinical scoring system for selection of patients for PTEN mutation testing is proposed on the basis of a prospective study of 3042 probands. Am J Hum Genet. 2011;88:42-56.

10. Lerner.ccf.org [Internet]. Genomic medicine institute. Risk calculator for estimating a patient's risk for pten mutation [cited 2017 Nov 22]. Available from: http://www. lerner.ccf.org/gmi/ccscore/.

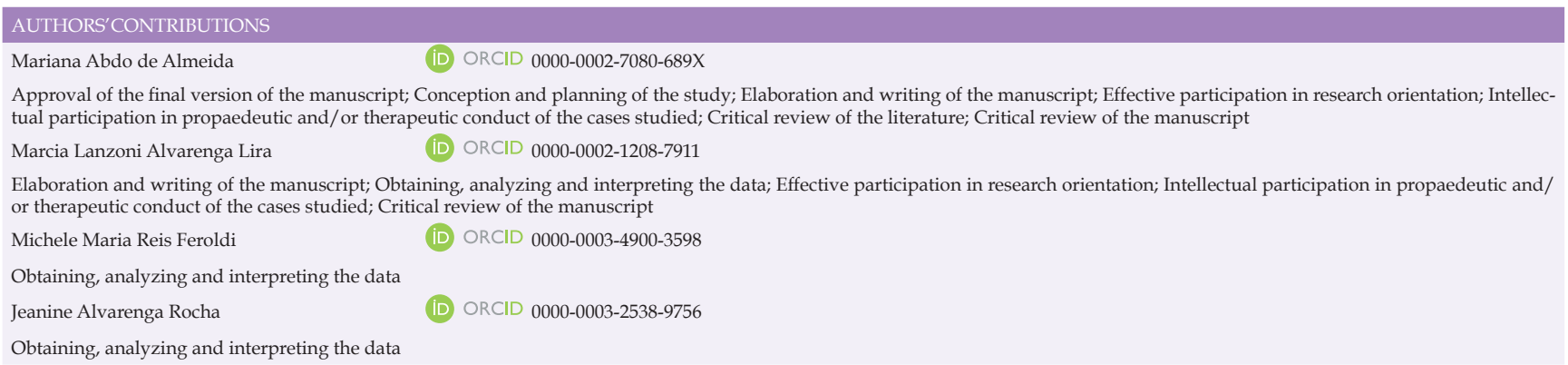

How to cite this article: Lira MLA, Almeida MA, Reis-Feroldi M, Rocha JA. Follicular thyroid carcinoma metastatic to skin: a small papule and a big change. An Bras Dermatol. 2019;94(1):76-8. 